\title{
7 Limitations of the Historical Study and Strategic Analysis
}

This thesis in hand is subject to several limitations mainly due to its research approach and the used sample. First of all, the analysis of the largest companies in Germany is purely descriptive. Based on the research question and on the given data this approach was chosen to show a comprehensive picture of the development of large family and non-family businesses. This should help to discover relevant topics and to raise new questions for future research to better understand the differences between family and non-family businesses as well as to extend the business administration of family companies. Nevertheless, due to this descriptive approach it is unclear if the shown interconnections can be generalized. Empirical research with a larger sample could help to support or refuse the findings of this thesis.

The limited access to corporate information due to the restricted availability, the reluctance of companies and the limited time frame to gather relevant primary sources has reduced the number of examinable variables. A more comprehensive dataset would help to increase the understanding of the growth and decline processes and would be much appreciated. Further, the limited access as well as the interpretation of the historical data by the author (especially regarding the event of a downfall) can cause a biased or an arguable strategic categorization although the research was conducted to the best of the knowledge and in all conscience. ${ }^{218}$ The empirical analyses based on the CAGR show averages of the developments of the companies over several years. Therefore, the real growth rates of each single year would be more precise to detect growth and decline steps but this approach would require even more data which is hardly to access.

Overall, despite the mentioned limitations it is shown that the growth and decline processes of large German family and non-family businesses especially due to their heterogeneity and unexplored interconnections are still offering interesting research questions. Further, because of the high importance of these topics for the corporate practices and strategies hopefully this and future research contributions will help to shape an even more comprehensive and detailed picture of these topics.

218 For the conscience in the science of history see among others Goertz (1995): p. 15 et seqq.

(C) Springer Fachmedien Wiesbaden GmbH 2017

M. Lantelme, The Rise and Downfall of Germany's Largest

Family and Non-Family Businesses, BestMasters,

DOI 10.1007/978-3-658-16169-9_7 